\title{
Gas turbine power calculation method of turboshaft based on simulation and performance model
}

\author{
Heng $\mathrm{Wu}^{1, *}$, Shufan Zhao ${ }^{1}$, Jijun Zhang ${ }^{2}$, Bo Sun $^{2}$, and Hanqiang Song ${ }^{3}$ \\ ${ }^{1}$ Aviation Foundation College, Naval Aviation University, Yantai Shandong 264001, China \\ ${ }^{2}$ Unit 91911, Sanya Hainan 572000, China \\ ${ }^{3}$ Institute of Aviation Equipment, Naval Academy of Armament, Shanghai 200436, China
}

\begin{abstract}
Gas turbine power of turboshaft engine cannot be measured, a total of five typical steady state point test data from the ground slow state to the maximum state were selected according to the factory acceptance test drive of a certain type of carrier-based helicopter turboshaft engine. Combustion chamber three-dimensional simulation model was established to carry on simulation analysis of different typical steady state combustion process. The simulated combustion chamber exit section parameters are input into the established gas turbine isentropic adiabatic aerodynamic calculation model to obtain the gas turbine power and outlet temperature. Select five typical steady state points of five sets of turboshaft engines on the same type to repeat the above calculation process, and compare the calculated value of gas turbine outlet temperature with the acceptance test values, it is found that the error values are all within 5\%, and the effectiveness and accuracy of the gas turbine power calculation method are verified.
\end{abstract}

\section{Introduction}

At present, engine output shaft power is used to evaluate engine performance. However, for turboshaft engines, the differences in load, adjustment method and use environment between bench acceptance test and installed flight make it impossible to analyse the loss of installed power due to airflow interference according to the value changes of engine output shaft power before and after the installed flight, so it is necessary to get the gas turbine power changes.

There are many researches on power calculation, power loss and performance degradation of different type of engines both at home and abroad [1-3]. However, the gas turbine power of the turboshaft engine is not measurable, for the data is limited and the accurate modelling is difficult, there is not much research on the calculation method of gas turbine power. In this paper, flow field simulation method [4-5] and aerodynamic modelling method [6-8] are used to carry out the gas turbine power calculation and verification research combining with the typical steady state point data of the test run, which has laid

\footnotetext{
* Corresponding author: wuheng89810@163.com
} 
the foundation for carrying out the power loss and performance degradation of a certain type of carrier-based helicopter engine and has important engineering application value [9$10]$.

\section{Gas turbine power calculation model of turboshaft}

\subsection{Combustion chamber calculation model by simulation}

Taking a certain type of carrier-based helicopter engine as an example, the threedimensional simulation model of the baffled combustion chamber with centrifugal oilthrowing device is used to simulate the combustion process under different typical steady states and the corresponding parameters such as the outlet temperature of the combustion chamber are obtained.

The atomization combustion process of the fuel in the combustion chamber mainly includes the flow and atomization of the fuel, the evaporation of the fuel in the temperature field, the blending combustion of the fuel vapor and the air, the component transport of the temperature field, the generation and emission of pollutants and so on. In this paper, the working process and structure of the baffled combustion chamber with centrifugal oil throwing device are analyzed. The simplified computational domain model of the combustion chamber and oil pan is obtained by using the feature extraction method and periodic boundary conditions are used for the calculation domain. The finite volume method is used to discretize the computational domain. Semi-implicit algorithm is used to solve the coupling of velocity and pressure in the flow field.

The basic idea of the finite volume method is: first, the calculated area is discrete approximately into a finite number of non-overlapping grid. Select a series of nonoverlapping control body units around each grid so that each control body unit contains only one node. Set the flow to be determined on the grid node, and then integrate each control unit to derive a set of discrete formats. Solve it and get the numerical solution of the flow.

The two-dimensional non-stick flow Euler equations:

$$
\begin{gathered}
\boldsymbol{u}_{t}+\boldsymbol{f}_{x}+\boldsymbol{g}_{y}=\boldsymbol{0} \\
\boldsymbol{u}=\left\{\begin{array}{l}
\rho \\
\rho u \\
\rho v \\
E
\end{array}\right\}, \quad \boldsymbol{f}=\left\{\begin{array}{l}
\rho u \\
\rho u^{2}+\rho \\
\rho u v \\
(E+p) u
\end{array}\right\}, \boldsymbol{g}=\left\{\begin{array}{l}
\rho v \\
\rho u v \\
\rho v^{2}+p \\
(E+p) v
\end{array}\right\}
\end{gathered}
$$

Its control unit is actually a surface unit. Integrate it in each control body:

$$
\int_{s}\left(\frac{\partial \boldsymbol{u}}{\partial t}+\frac{\partial \boldsymbol{v}}{\partial x}+\frac{\partial \boldsymbol{g}}{\partial y}\right) \mathrm{d} x \mathrm{~d} y=\mathbf{0}
$$

where $\mathrm{s}$ is the control body cell area. Using Gauss's theorem, the $\frac{\partial \boldsymbol{f}}{\partial x}, \frac{\partial \boldsymbol{g}}{\partial y}$ unit area points are transformed into the boundary line integrals:

$$
\frac{\mathrm{d}}{\mathrm{d} t} \int_{s} \boldsymbol{u} \mathrm{d} x \mathrm{~d} y+\int_{t}\left(\boldsymbol{f} \cdot \boldsymbol{n}_{x}+\boldsymbol{g} \cdot \boldsymbol{n}_{y}\right) \mathrm{d} l=\boldsymbol{0}
$$

The equation is applied to all control volume elements, and the discrete format of the whole calculation area is obtained. The two-dimensional Euler equations are solved under a certain initial boundary condition, and its numerical solution is obtained.

In the aspect of fuel atomization, a discrete phase model is used to describe the atomization process of the oil pan. In combustion simulation, the burn rate is fast for most 
fuels, and the overall rate of combustion is dominated by the turbulent mixing process. In non-premixed combustion, turbulence slowly convects and mixes the fuel and oxidant to the reaction zone, then it combusts quickly. The reaction between fuel vapor and air studied in this paper belongs to non-premixed combustion. Therefore, the chemical reaction process is directly calculated by ED model with high computational efficiency. Fluent obtains the local mass fraction $Y_{i}$ for each component by solving the convection-diffusion equation of the $i$ th component, the equation adopts the following general form:

$$
\frac{\partial}{\partial t}\left(\rho Y_{i}\right)+\nabla \cdot\left(\rho \vec{v} Y_{i}\right)=-\nabla \cdot \vec{J}_{i}+R_{i}+S_{i}
$$

where $S_{i}$ is the rate of mass gain added to the $i$ th component from the discrete or custom source term. In the model established in this paper, $S_{i}$ mainly comes from fuel droplets. $R_{i}$ is the net productivity of the $i$ th component by a chemical reaction, the generation rate of the component $i$ in the chemical reaction $r$ is calculated by the following formula in ED model.

$$
R_{i, r}=v_{i, r}^{t} M_{w, i} A B \rho \frac{\varepsilon}{k} \frac{\sum P Y_{P}}{\sum_{j}^{N} v_{j, r}^{t t} M_{w, j}}
$$

where $Y_{P}$ is the mass fraction of any product component $\mathrm{P}, Y_{\mathrm{R}}$ is the mass fraction of a specific reactant $\mathrm{R}$ and $v_{i, r}^{t}$ is the chemical equivalent coefficient of the component $i$ in the chemical reaction $r$.

After the calculation is completed, the mass fraction of reactants and products and the distribution of the flow field parameters are further obtained. By using the above methods, combined with the parameters collected by the bench acceptance test drive, reasonable boundary conditions are given to ensure the closure of the control equations. The geometry of baffling combustor with centrifugal oil throwing device is shown in Figure 1. The calculation area of the combustion chamber after simplify and the division of the grid are shown in Figure 2.

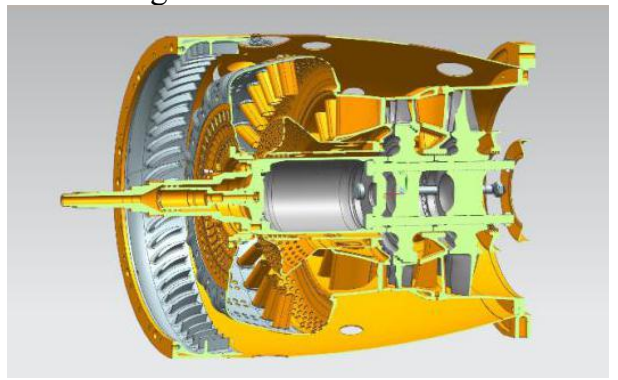

Fig. 1. The geometry of baffling combustor with centrifugal oil throwing device

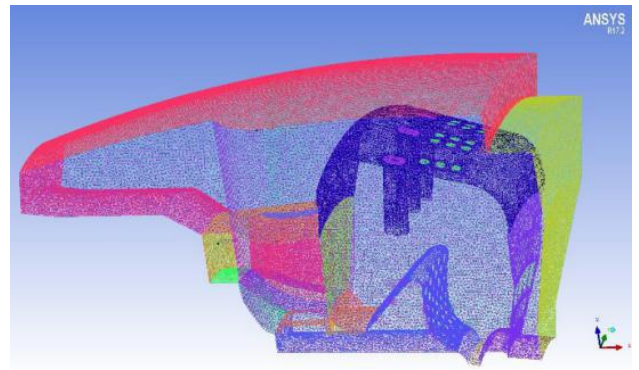

Fig. 2. The calculation area of the combustion chamber after simplify and the division of the grid

\subsection{Gas Turbine Power Performance Calculation Model}

The gas flow into the gas turbine $W_{5 a}$ is the sum of the air flow $W_{4}$ and the fuel flow $W_{f}$. According to the engine speed $n_{g}$ at different steady states and the gas turbine characteristic data, the pressure ratio $\pi_{g t}$ and the efficiency $\eta_{g t}$ of the gas turbine with different steady states can be interpolated.

The gas turbine expansion work process can be seen as the adiabatic process of adiabatic, so the definition of entropy can be obtained according to the relationship between temperature and pressure as shown in (7). 


$$
d s=\frac{d Q}{T}=\frac{c_{p} d T-v d P}{T}=\frac{c_{p} d T}{T}-R \frac{d P}{P}
$$

Set the start and end states of gas through the gas turbine as 1 and 2, the (7) integral can be obtained:

$$
\begin{gathered}
S_{2}-S_{1}=\int_{T_{1}}^{T_{2}} \frac{c_{p} d T}{T}-R \ln \frac{P_{2}}{P_{1}}=0 \\
\int_{T_{1}}^{T_{2}} \frac{c_{p} d T}{T}=R \ln \frac{P_{2}}{P_{1}}
\end{gathered}
$$

From (9), it can be seen that the relationship between temperature $T$ and pressure $P$ is affected by the heat capacity of constant pressure ratio $c_{p}$, and if the temperature and composition of gas change, $c_{p}$ will also change. The size of the integral item on the left side of equation (9) is only determined by the temperature of the starting and ending states.

$$
\int_{T_{1}}^{T_{2}} \frac{c_{p} d T}{T}=\phi\left(T_{2}\right)-\phi\left(T_{1}\right)
$$

According to equation (9) and equation (10), (11) can be obtained.

$$
\begin{aligned}
\phi_{2}-\phi_{1}= & R \ln \left(\frac{P_{2}}{P_{1}}\right) \\
& =R \ln \pi
\end{aligned}
$$

For convenience of calculation, the formula (11) is expressed as ordinary logarithm:

$$
\phi_{2}-\phi_{1}=\frac{R}{\lg (e)} \lg \pi
$$

Set $\varphi=\frac{\lg (e)}{R} \phi$, Substituting (12) into a more concise relation:

$$
\varphi_{2}-\varphi_{1}=\lg \pi
$$

$\varphi$ is known as the entropy function, thus obtaining the basic equation for calculating the parameters of the adiabatic process. The thermodynamic properties of air corresponding to this are given in [11]. The values of $c_{p}, H$ and $\varphi$ of the air functions at different temperatures are listed in the table and are not given here. To calculate the gas $c_{p g}, H_{g}, \varphi_{g}$, the air parameter can be corrected by the ratio of gas to oil $f$ and the correction factor $\theta_{c_{p}}, \theta_{H}$ and $\theta_{\varphi}$. The formula is as follows:

$$
\begin{aligned}
& c_{p g}=c_{p}+\frac{f}{1+f} \theta_{c_{p}} \\
& H_{g}=H+\frac{f}{1+f} \theta_{H} \\
& \varphi_{g}=\varphi+\frac{f}{1+f} \theta_{\varphi}
\end{aligned}
$$

In addition, the fitting formula between $c_{p}, H, \varphi, \theta_{c_{p}}, \theta_{H}, \theta_{\varphi}$ and $T$ is given in [11]. Therefore, the total gas turbine total entropy and total enthalpy and the gas-oil ratio can be calculated according to the simulation of the gas turbine forward temperature as follows:

$$
\begin{aligned}
f_{g t} & =\frac{W_{f}}{W_{5 a}} \\
h_{5 a}^{*} & =f\left(T_{5 a}^{*}\right) \\
s_{5 a}^{*} & =\varphi\left(T_{5 a}^{*}\right)
\end{aligned}
$$


According to the relation of entropy function, the ideal entropy function $S_{5, i}^{*}$ of gas turbine exit can be calculated, then the ideal total temperature $T_{5}^{*}$ of turbine outlet can be obtained through iteration according to the variable heat ratio fitting formula. The ideal total enthalpy $h_{5, i}^{*}$ can be calculated by the ideal total temperature.

$$
\begin{array}{r}
s_{5, i}^{*}=s_{5 a}^{*}-\lg \pi_{g t} \\
T_{5, i}^{*}=\varphi^{-1}\left(s_{5, i}^{*}\right) \\
h_{5, i}^{*}=f\left(T_{5, i}^{*}\right)
\end{array}
$$

According to the definition of gas turbine efficiency, the turbine efficiency is equal to the ratio of actual specific power to ideal specific power. The total enthalpy $h_{5, i}$ of the turbine outlet can be obtained according to this, and the total temperature $T_{5, i}$ of the turbine outlet can be obtained by iteratively using the variable specific heat fitting formula.

$$
\begin{array}{r}
h_{5}^{*}=h_{5 a}^{*}-\left(h_{5 a}^{*}-h_{5, i}^{*}\right) \eta_{g t} \\
T_{5}^{*}=f^{-1}\left(h_{5}^{*}\right)
\end{array}
$$

The gas turbine power is equal to the actual enthalpy of the gas passing through the turbine multiplied by the gas flow, and the power $P_{g t}$ of the gas turbine is calculated.

$$
P_{g t}=\left(h_{5 a}^{*}-h_{5}^{*}\right) \times W_{5}
$$

\section{Calculation and Verification of Gas Turbine Power under Typical Operating Conditions}

Five typical stable state point test data from the on-ground idle state to the maximum state were selected according to the factory acceptance test drive of five same-type turboshaft engines, and the power generated by the gas turbine and gas turbine outlet temperature were calculated by using the gas turbine power calculation method. Comparing the calculation value of the gas turbine outlet temperature with the acceptance test measurements under different states, and calculate the error values. The temperature distribution of a symmetrical section of the combustion chamber calculated by the simulation at one of the typical steady state points of an engines is shown in Figure 3. The typical steady state point data of the engine acceptance test is shown in Table 1. The calculated values of the gas turbine power and gas turbine outlet temperature and the comparison of acceptance test measured values are shown in Table 2 .

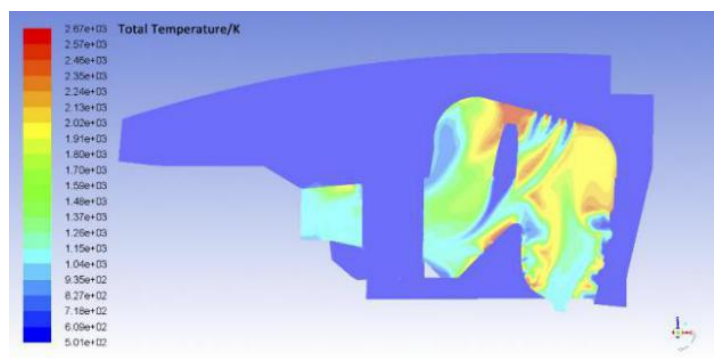

Fig. 3. Combustion chamber calculation domain symmetry section temperature distribution. 
Table 1. Typical steady state point data of bench acceptance test.

\begin{tabular}{|c|c|c|c|c|c|c|}
\hline $\begin{array}{c}\text { Intake air } \\
\text { temperature } \\
\left({ }^{\circ} \mathrm{C}\right)\end{array}$ & $\begin{array}{c}\text { Atmospheric } \\
\text { pressure } \\
(\mathrm{Pa})\end{array}$ & $\begin{array}{c}\text { Gas } \\
\text { generator } \\
\text { speed } \\
\mathrm{ng}(\mathrm{r} / \mathrm{min})\end{array}$ & $\begin{array}{c}\text { Air flow } \\
\text { qma } \\
(\mathrm{kg} / \mathrm{s})\end{array}$ & $\begin{array}{c}\text { Fuel } \\
\text { consumption } \\
(\mathrm{L} / \mathrm{h})\end{array}$ & $\begin{array}{c}\text { Pressure } \\
\text { ratio } \pi \mathrm{c} . \mathrm{t}\end{array}$ & $\begin{array}{c}\text { Gas generator } \\
\text { outlet } \\
\text { temperature } \\
\text { t42.t( }\left({ }^{\circ} \mathrm{C}\right)\end{array}$ \\
\hline 9.11 & 102277.463 & 19959.86 & 2.965 & 131.646 & 2.169 & 405.838 \\
\hline 9.616 & 102249.884 & 25037.542 & 4.5 & 223.213 & 3.308 & 452.717 \\
\hline 9.429 & 102256.779 & 30040.119 & 5.819 & 394.488 & 5.039 & 592.457 \\
\hline 9.124 & 102270.568 & 32400.862 & 6.618 & 539.86 & 6.055 & 728.332 \\
\hline 9.024 & 102277.463 & 33225.902 & 6.86 & 589.444 & 6.403 & 772.625 \\
\hline
\end{tabular}

Table 2. Calculated data and the comparison with the measured value.

\begin{tabular}{|c|c|c|c|}
\hline $\begin{array}{c}\text { Gas turbine outlet } \\
\text { temperature measured value } \\
\mathrm{t} 42 . \mathrm{t}\left({ }^{\circ} \mathrm{C}\right)\end{array}$ & $\begin{array}{c}\text { Gas turbine outlet } \\
\text { temperature calculated } \\
\text { value } 42 . \mathrm{t}\left({ }^{\circ} \mathrm{C}\right)\end{array}$ & $\begin{array}{c}\text { Error } \\
\text { value }(\%)\end{array}$ & $\begin{array}{c}\text { Power delivered by the } \\
\text { gas turbine Pgt }(\mathrm{KW})\end{array}$ \\
\hline 405.838 & 392.244 & $3.35 \%$ & 339.6 \\
\hline 452.717 & 436.746 & $3.53 \%$ & 704.1 \\
\hline 592.457 & 578.03 & $2.44 \%$ & 1249.2 \\
\hline 728.332 & 707.935 & $2.8 \%$ & 1353.7 \\
\hline 772.625 & 741.007 & $4.09 \%$ & 1394.1 \\
\hline
\end{tabular}

According to the results in Table 2, under different steady states, the error values of the calculated and measured values of gas turbine exit temperatures are all within $5 \%$. The error value distributions of several other engines are shown in Figure 4.

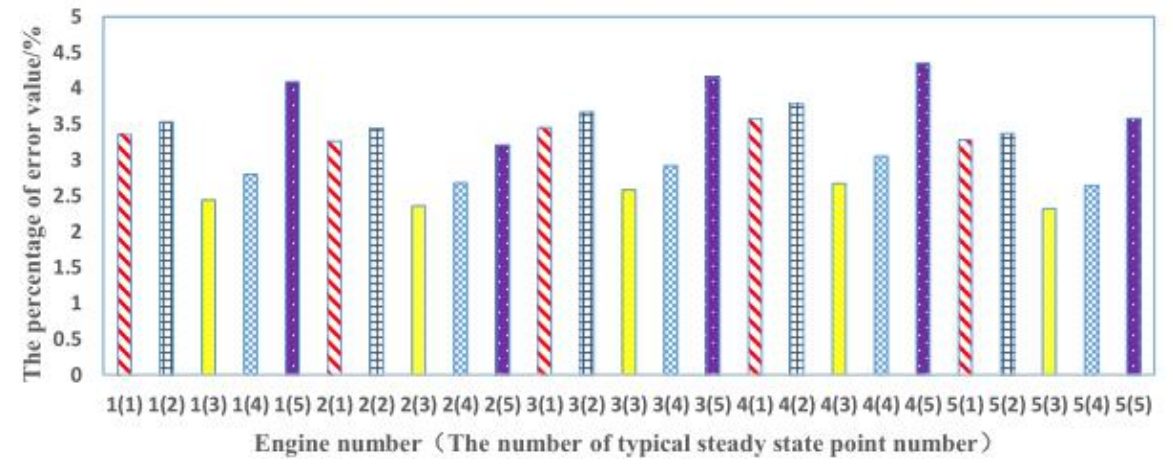

Fig. 4. The error value distributions of five selected engines at five typical steady state points.

It can be seen in Figure 4 that the error values are all within acceptable error limits of the engineering application, thus verifying the accuracy and reliability of the combustion chamber simulation model and the gas-turbine isentropic adiabatic aerodynamic model.

\section{Conclusion}

In this paper, the gas turbine power calculation method of a turboshaft engine is studied by means of flow field simulation, numerical modeling and test data verification. gas turbine exit temperatures of a certain turboshaft engine are calculated under five typical steadystate from the local slow-moving vehicle to the maximum state by using the established three-dimensional simulation model of the baffled combustor with centrifugal oil thruster and the isentropic adiabatic aerodynamic thermodynamic model, and compare the 
calculated values with the factory acceptance test values, it is found that the error values are all within $5 \%$, thus the effectiveness and accuracy of the gas turbine power calculation method are verified.

\section{Acknowledgments}

Thanks for the financial support from special funds of Taishan Scholar Project.

\section{References}

1. CAI J B and HU B A Analysis of technical characteristics of high-power turboshaft engine used by heavy helicopter (Advances in Aeronautical Science and Engineering vol 5) pp 12-17 (2014)

2. ZHANG Z Development of military turboshaft engine (Aeroengine, vol 37) pp 58-62 (2011)

3. CALZADA $\mathrm{P}$ D L VILLANUEVA $\mathrm{M}$ A PARRA J et al Design and development of the inter-turbine structure and power turbine for MTR390-E turboshaft engine (ASME Turbo Expo: Turbine Technical Conferene and Exposition) GT201394021 (2013)

4. NKOI B PILIDIS P NIKOLAIDIS T Performance assessment of simple and modified cycle turboshaft gas turbines (Propulsion and Power Research vol 2) pp 96-106 (2013)

5. TANG H L ZHANG K GUO K et al Quantification method of effects of uncertainty on component performance for turboshaft engine performance (Journal of Propulsion Technology vol 36) pp 1143-50 (2015)

6. CHEN M ZHANG K TANG H L A probabilistic design methodology for a turboshaft engine overall performance analysis (Advances in Mechanical Engineering vol 8) pp 1-12 (2014)

7. ZHAO Q CHEN Y C WANG Y W et al Study of mathematical model on steadycharacteristics of turboshaft engine based on component modeling (Advances in Aeronautical Science and Engineering vol 2) pp 312-17 (2011)

8. ONDER T AYDIN H Numerical calculation of energy and exergy flows of a turboshaft engine for power generation and helicopter applications (Energy vol 115) pp 914-23 (2016)

9. POPESCU J A VILAG V CUCIUMITA $\mathrm{C} F$ et al Theoretical and numerical approaches for calculating the performances of an industrial turboshaft (Applied Mechanics and Materials vol 555) pp 121-26 (2014)

10. SHAN X M HUANG J Q ZHOU W X et al Study and test validation of turboshaft engine on-line performance monitoring technology (Journal of Aerospace Power vol 28) pp 721-29 (2013)

11. ZHU X J WANG X Y Working principle and performance of gas trubine (Beijing: Science Press) pp 502-16 (1992) 